\title{
Erratum to: Experimental Verification on the Hypothesis about the Possibility of Molecular Diagnostics of Local Tumor Spread on the Lewis Lung Carcinoma Model
}

T. A. Bogush ${ }^{a, ~ *}$, M. A. Maiak ${ }^{a, b}$, N. S. Saprykina $a$, A. A. Basharina ${ }^{a}$, O. M. Ryabinina ${ }^{a}$, A. N. Grishanina ${ }^{a}$, E. A. Bogush ${ }^{c}$, A. A. Kamensky ${ }^{d}$, and V. S. Kosorukov ${ }^{a}$

${ }^{a}$ Blokhin Russian Cancer Research Center, Ministry of Health of the Russian Federation, Moscow, Russia

${ }^{b}$ Russian State Agrarian University-Timiryazev Moscow Agricultural Academy, Moscow, Russia

${ }^{c}$ Sklifosovsky Institute of Clinical Medicine, Sechenov University, Ministry of Health of the Russian Federation, Moscow, Russia

${ }^{d}$ Lomonosov Moscow State University, Moscow, Russia

*e-mail: tatbogush@mail.ru

Submitted September 8, 2021; accepted for publication September 8, 2021

DOI: $10.3103 / \mathrm{S} 0027131421060109$

The article was mistakenly published as an Open Access article.

The original article has been corrected.

The original article can be found online at https://doi.org/10.3103/S0027131421040039 